\title{
Towards a Smart Manufacturing Maturity Model for SMEs $\left(\mathbf{S M}^{3} \mathbf{E}\right)$
}

\author{
Sameer Mittal ${ }^{1}$, David Romero ${ }^{2}$, Thorsten Wuest ${ }^{1}$ (corr. author) \\ ${ }^{1}$ Industrial and Management Systems Engineering, Benjamin M. Statler College of \\ Engineering and Mineral Resources, West Virginia University, Morgantown, WV, USA \\ samittal@mix.wvu.edu, thwuest@mail.wvu.edu \\ ${ }^{2}$ Tecnológico de Monterrey, Mexico \\ david.romero.diaz@gmail.com
}

\begin{abstract}
This paper proposes a new Smart Manufacturing Maturity Model for small and medium-sized Enterprises $\left(\mathrm{SM}^{3} \mathrm{E}\right)$. The $\mathrm{SM}^{3} \mathrm{E}$ maturity model supports SMEs during the challenging digital transformation journey and paradigm shift towards Smart Manufacturing and Industry 4.0 on three-axis: (i) organizational dimensions, (ii) toolboxes, and (iii) maturity levels. The $\mathrm{SM}^{3} \mathrm{E}$ maturity model development was based on a literature and critical review as well as interviews conducted during industrial visits. During these visits, SME specific requirements were collected, assessed and taken into account during the development of the $\mathrm{SM}^{3} \mathrm{E}$ maturity model. Overall, an analysis of maturity levels, based on the working methods and toolboxes of our $\mathrm{SM}^{3} \mathrm{E}$ maturity model will help SMEs to progress towards Smart Manufacturing and Industry 4.0.
\end{abstract}

Keywords: Digitalization, SMEs, Industry 4.0, Smart Manufacturing, Intelligent Manufacturing, Maturity Model, Working Methods, Toolboxes, Toolkit.

\section{Introduction}

Small and Medium-sized Enterprises (SMEs), especially those in the manufacturing sector, have always been considered as the backbone of the economy [1-4] for both developed and developing countries. However, their perspective has not always been taken into account when it comes to the framing of appropriate Industry 4.0 policies. Similarly is the case for the guidelines of Smart Manufacturing Initiatives in countries such as the U.S. (i.e., Smart Manufacturing), Germany (i.e., Industrie 4.0) and South Korea (i.e., Smart Factory) where specific directions for SMEs are missing [5-6]. These SM Initiatives aim at accelerating the growth of the economy by capitalizing on the new digital engines of growth (e.g., connectivity, intelligence, and flexible automation) offered by the Fourth Industrial Revolution (I4). Nevertheless, by not considering the perspective of SMEs, their confined growth might have adverse effects on the overall growth of the economy and creation of true smart global value chains.

Maturity models are capable of identifying a set of "conditions when the examined objects reach the best (perfect) state for their intended purpose" [7]. Although literature shows several SM/Industry 4.0 maturity models for large enterprises [e.g., 8-16], it fails to present an SME perspective. The organizational dimensions and maturity levels for large enterprises need to be altered to reflect the different requirements of SMEs. Thus far, there are no "self-assessment methods" for SMEs, which support their digital transformation. Therefore, SMEs are often forced to either hire external experts (e.g., 
consultants or service providers), and thus straining their already limited resources, or slow down their activities to ramp-up their Smart Manufacturing (SM) journey.

This paper is divided into five sections. Section 1 presents the overall research problem. Section 2 identifies the research gap based on current literature and critical review augmented by interviews conducted during industrial visits to SMEs. Section 3 introduces our $\mathrm{SM}^{3} \mathrm{E}$ maturity model, a three-axis model composed by organizational dimensions, toolboxes and maturity levels. Section 4 presents an exemplary application of the $\mathrm{SM}^{3} \mathrm{E}$ maturity model's 'cloud/storage toolbox' towards the development of the SM capability 'data-driven decision making'. Section 5 concludes the paper with a summary of the results, limitations and an outlook on future work.

\section{Literature Review}

The most popular, based on citations, maturity models in the literature [8-16] do not sufficiently reflected an $S M E$ specific perspective and their unique requirements when it comes to adopting the SM/Industry 4.0 paradigm. Table 1 depicts nine current maturity models that mainly cater for large enterprises and do not represent SMEs' specific requirements. Only [10] has partially considered an SME perspective, but falls short in clearly defining 'organizational dimensions', thus making its utilization unrealistic for SMEs. Hence, organizational dimensions represent the organizational areas and/or enterprise functions of an organization, and the maturity levels provide a stepwise approach towards "maturity" in each of these organizational dimensions [17].

Table 1. Maturity Models' Dimensions and Levels

\begin{tabular}{|c|c|c|c|}
\hline Paper & Organizational Dimensions & Maturity Levels & SME Persp. \\
\hline$[8]$ & $\begin{array}{l}\text { Nine dimensions: strategy, leadership, } \\
\text { customers, products, operations, culture, } \\
\text { people, governance, and technology. }\end{array}$ & Not defined. & Not considered \\
\hline [9] & $\begin{array}{l}\text { Four dimensions: organizational maturity, } \\
\text { information technology maturity, } \\
\text { performance management maturity, and } \\
\text { information connectivity maturity. }\end{array}$ & $\begin{array}{l}\text { Activity maturing scoring scale } \\
\text { based on a task-score of } 0 \text { to } 9 \text { : } \\
\text { not performed (0), initial (1), } \\
\text { managed (3), defined (5), } \\
\text { qualitative (7), optimizing (9) }\end{array}$ & Not considered \\
\hline$[10]$ & Not defined. & $\begin{array}{l}\text { Three stage maturity model: } \\
\text { initial, managed, and defined. }\end{array}$ & Considered \\
\hline$[11]$ & $\begin{array}{l}\text { Six dimensions: strategy and organization, } \\
\text { smart factory, smart operations, smart } \\
\text { products, data-driven services, and } \\
\text { employees. }\end{array}$ & $\begin{array}{l}\text { Six stage maturity model: } \\
\text { outsider, beginner, } \\
\text { intermediate, experienced, } \\
\text { expert, top performer }\end{array}$ & Not considered \\
\hline$[12]$ & $\begin{array}{l}\text { Seven dimensions: digital business models } \\
\text { and customer access, digitization of product } \\
\text { and service offerings, digitization and } \\
\text { integration of vertical and horizontal value } \\
\text { chains, data \& analytics as core-capability, } \\
\text { agile IT architecture, compliance security, } \\
\text { legal and tax, and organization employees } \\
\text { and digital culture. }\end{array}$ & $\begin{array}{l}\text { Four stage maturity model: } \\
\text { digital novice, vertical } \\
\text { integration, horizontal } \\
\text { collaborator, and digital } \\
\text { champion. }\end{array}$ & Not considered \\
\hline$[13]$ & $\begin{array}{l}\text { Four dimensions: resources, information } \\
\text { systems, organization structure and } \\
\text { organizational culture. }\end{array}$ & $\begin{array}{l}\text { Six stage maturity model: } \\
\text { computerization, connectivity, } \\
\text { visibility, transparency, } \\
\text { predictability, and adaptability. }\end{array}$ & Not considered \\
\hline
\end{tabular}




\begin{tabular}{|c|l|l|l|}
\hline$[14]$ & $\begin{array}{l}\text { Four dimensions: information infrastructure, } \\
\text { (incl. hard- / software), controls \& devices } \\
\text { (e.g., sensors, actuators, motor controls, } \\
\text { switches, and feed \& receive data), networks } \\
\text { (enabling information exchange), and } \\
\text { security policies. }\end{array}$ & $\begin{array}{l}\text { Five stage maturity model: } \\
\text { assessment, secure and } \\
\text { upgraded network and controls, } \\
\text { defined and organized working } \\
\text { data capital, analytics, and } \\
\text { collaboration. }\end{array}$ & Not considered \\
\hline$[15]$ & $\begin{array}{l}\text { Five dimensions: asset management, data } \\
\text { governance, application management, } \\
\text { process transformation, and organizational } \\
\text { alignment. }\end{array}$ & $\begin{array}{l}\text { Six level (0-5) maturity model: } \\
\text { incomplete, performed, } \\
\text { managed, established, } \\
\text { predictable, and optimizing. }\end{array}$ & Not considered \\
\hline$[16]$ & $\begin{array}{l}\text { Three dimensions: smart products and } \\
\text { services, smart business processes, and } \\
\text { strategy and organization. }\end{array}$ & $\begin{array}{l}\text { Four level (0-3) maturity } \\
\text { model: absence, existence, } \\
\text { survived, and maturity. }\end{array}$ & Not considered \\
\hline
\end{tabular}

\section{Towards a Smart Manufacturing Maturity Model for SMEs}

Maturity models often define each of their levels in terms of components and subcomponents, and the validity of these elements is mainly confirmed with the help of industrial surveys [18]. This makes maturity models a viable option to support manufacturing SMEs towards successfully realizing SM/Industry 4.0 capabilities.

Our proposed $S M^{3} E$ maturity model is a three-axis model (see Fig. 1), addresses five key organizational areas and/or enterprise functions of an SME, from now on referred to as organizational dimensions (X-axis), includes a modular toolkit composed of seven individual complementary toolboxes (Y-axis), which supports a stepwise approach through five maturity levels (Z-axis).

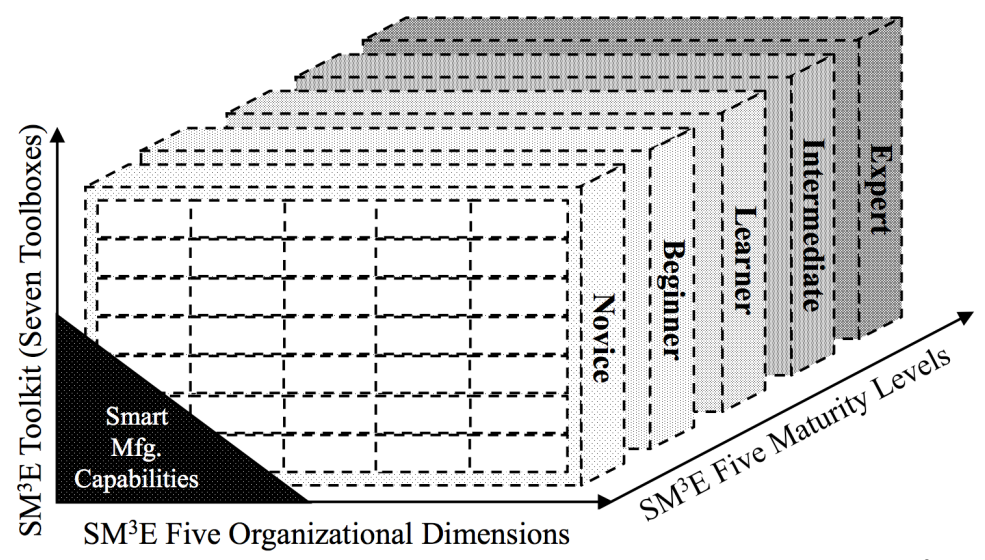

Fig. 1. The Smart Manufacturing Maturity Model for SMEs $\left(\mathrm{SM}^{3} \mathrm{E}\right)$

By adopting our $S M^{3} E$ maturity model, an SME will be able to assess and place itself in one of five maturity levels for each of its five key organizational dimensions. Thus, the SME would be able to identify the input and/or support required to reach the next level of maturity in an organization dimension, which can be provided by dedicated toolboxes. A toolbox enables an SME to perform more sophisticated activities in the respective dimension(s). The next sub-sections detail each of the three-axes of the $S M^{3} E$ maturity model: organizational dimensions, maturity levels and toolboxes. 


\section{1 $\mathrm{SM}^{3} \mathrm{E}$ Organizational Dimensions}

SM is about the connectivity, virtualization, and data utilization of manufacturing systems and beyond. The main focus is on manufacturing operations' performance. However, there are other organizational dimensions, beyond the purely technical ones, that have not yet been included in current maturity models. An example of such nontechnical organizational dimensions is "finance". In order to truly support a holistic digital transformation of an enterprise those have to be reflected in the maturity model as well. Hence, in order to provide the best possible support to an SME that is willing to start its SM journey, the SME must be holistically informed about all the benefits of achieving the highest maturity level of the respective organizational dimensions. This information will build confidence and motivate the SME to move towards the development of SM/Industry 4.0 capabilities. SMEs have to balance different factors stemming from the evolution of manufacturing systems [19]. We took this into careful consideration when designing the organizational dimensions and sub-dimensions included in the $\mathrm{SM}^{3} \mathrm{E}$ maturity model (see Table 2). They all were selected based on the alignment with an SME perspective and their specific requirements and are aimed to "mimic" the typical organization structure and basic enterprise functions of a small business for easier adoption by SME managers during the SM journey.

Table 2. Organizational Dimensions and Sub-dimensions of $\mathrm{SM}^{3} \mathrm{E}$ Maturity Model

\begin{tabular}{|c|c|c|c|c|c|}
\hline Dim. & Finance & People & Strategy & Process & Product \\
\hline $\begin{array}{l}\text { Sub- } \\
\text { dim. }\end{array}$ & $\begin{array}{l}\text { - Cost-Benefit } \\
\text { Analysis } \\
\text { - Budgeting and } \\
\text { Costs Control } \\
\text { - Investments } \\
\text { Risk and } \\
\text { Returns } \\
\text { Management }\end{array}$ & $\begin{array}{l}\text { - Leadership } \\
\text { - Customer } \\
\text { Feedback } \\
\text { - Safety and } \\
\text { Ergonomics } \\
\text { - Training and } \\
\text { Education }\end{array}$ & $\begin{array}{l}\text { - Knowledge } \\
\text { Management } \\
\text { - Decision Support/ } \\
\text { Decision Making } \\
\text { - Standards } \\
\text { - Legal/Tax Policies } \\
\text { - Sustainability } \\
\text { Guidelines } \\
\text { - Government } \\
\text { Regulations }\end{array}$ & $\begin{array}{l}\text { - Quality Control } \\
\text { - Job Scheduling } \\
\text { - Repair and } \\
\text { Maintenance } \\
\text { - Machines } \\
\text { Operation } \\
\text { - Flexibility }\end{array}$ & $\begin{array}{l}\text { - Logistics } \\
\text { - New Product } \\
\text { Development } \\
\text { - Packaging } \\
\text { - Modularity } \\
\text { - Time to Market }\end{array}$ \\
\hline
\end{tabular}

Dimension 1: Finance. This dimension is focussing on how the SME is managing its economics (i.e., financial accounting). Existing data is often managed in the form of balance sheets, income statements, cash flow statements, and investment portfolios. Cost-benefit analysis, budgeting, and costs control, as well as investments risk and return management, are the SME's primary concerns (sub-dimensions). In this sense, an accounting computer-based information system can provide a transparent and secure method (data) to help SMEs to manage their SM project.

Dimension 2: People. This dimension considers different organizational and cultural aspects such as an encouraging "leadership" and vision towards SM/Industry 4.0 [8] [20]. An organizational culture that is prepared to learn and evolve as well as to look ahead is positive for employee motivation [9] [11] [13] [15], and "customer feedback" in product development [8]. However, there may be some additional subdimensions that organizations need to consider, such as employees "safety and ergonomics" practices in order to have more productive employees and avoid medical expenditure due to occupational accidents. Here, data exists in the form of payroll- 
sheets (e.g., number of employees) and work schedules-sheets (e.g., workhours, shifts), which can help SMEs to better manage the personnel involved in their SM project. Moreover, allowing employees to attend workshops and seminars will help them to embrace new working methods and technologies, and up-skill/re-skill themselves (i.e., training and education) for the new Industry 4.0 workplace.

Dimension 3: Strategy. This dimension has been previously discussed in the literature [8] [16]. However, this dimension might overwhelm SMEs since they are more likely to focus on tactics and operations to run their daily business. When it comes to the SM journey, the most important 'strategy' for an SME, currently missing in literature, is how to utilize its data strategically (i.e., data/information/knowledge management). Unlike many large enterprises, SMEs do not have an enormous amount of data readily available. However, SMEs have the versatile expertise of their employees, who often work in different domains and if their experience is augmented by supporting data (i.e., other computer-based enterprise information systems), the SME might be able to make better decisions. Similarly, "decision-making" should involve employees from different areas, rather than just relying on the instinct and limited market research of the SME managers. Moreover, SMEs are not always fully aware of the "industrial standards" they need to obey - e.g., new "legal \& tax policies", "sustainability guidelines", and "government regulations" that might benefit their growth (i.e., incentives). Therefore, 'strategy' is another important dimension of our $S M^{3} E$ model, where data occurs in the form of targets, performance metrics, ranks, etc.

Dimension 4: Process. The steps involved in the transformation of a product from raw material to final product fall under the 'process' organizational dimension. This dimension has been considered by [20] as a key element for measuring the potential of an SME for becoming a smart factory. The key aspects (or sub-dimensions) of this organizational dimension are: "quality control", "job scheduling", "repair and maintenance", "machines operation", and "flexibility" [21]. Furthermore, data exists in the form of process parameters, machine downtimes, etc., documented in manuals and spreadsheets. Therefore, it is important to provide clear instructions to support employees in the execution of the key business processes of a manufacturing SME (i.e., sales, manufacturing, and delivery).

Dimension 5: Product. This organizational dimension includes the business activities (or sub-dimensions) of "logistics", "new product development", "packaging", "product modularity", and "time to market" [21]. In this case, data exists in the form of product specifications, the number of products, etc. The 'product' organizational dimension considers product logistics inside and outside the shopfloor environment, the development of new products, and making the product(s) available by reducing the time-to-market.

\section{2 $\mathrm{SM}^{3} \mathrm{E}$ Maturity Levels}

The $\mathrm{SM}^{3} \mathrm{E}$ model acknowledges the common number of levels in maturity models (e.g., CMMI), and considers the following five levels: (i) Novice represents organizations, largely unaware of the SM/Industry 4.0 paradigm, (ii) Beginner signifies a recent awareness and basic notion of the SM/Industry 4.0 paradigm, (iii) Learner stands for 
an SME that has started to experiment with SM/Industry 4.0 technologies, (iv) Intermediate implies successful pilot projects with SM/Industry 4.0 technologies in different organizational domains, finally (v) Expert embodies an SME deploying $\mathrm{SM}$ /Industry 4.0 technologies in a strategic way, and therefore it might be referred to as an "SME 4.0".

\subsection{SMㄹ E Toolkit (Toolboxes)}

A toolkit is a set of methods, tools, and practices that can lead towards a final goal [22]. The $S M^{3} E$ maturity model toolkit is composed of seven toolboxes: (i) manufacturing/ fabrication toolbox, (ii) design and simulation toolbox, (iii) robotics and automation toolbox, (iv) sensors and connectivity toolbox, (v) cloud/storage toolbox, (vi) data analytics toolbox, and (vii) business management toolbox (please read [22] for details on the SM toolkit). The rationale behind these seven toolboxes is to include various technologies, skills and business practices that can serve both the technical and managerial aspects required in an SME to adopt the SM/Industry 4.0 paradigm.

\section{Exemplary Usage of the $\mathrm{SM}^{3} \mathrm{E}$ Cloud/Storage Toolbox}

Due to pages length limitation, only the application/usage of the $S M^{3} E$ maturity model's cloud/storage toolbox will be detailed in this paper as an example. The toolbox focuses on "data/information storage support" as an enabler for "data-driven decision making", and it needs different "input requirements" depending on its maturity level like registers, logbooks and spreadsheets (novice), built-in hard drives (beginner), shared hard drives (HDs) (learners), cloud computing (intermediate), and fog computing (expert) in order to create a "data-rich environment" to successfully support decisionmaking in an SM environment (see Table 3).

Table 3. SM ${ }^{3}$ E Maturity Model's Cloud/Storage Toolbox

\begin{tabular}{|c|c|c|c|c|c|}
\hline Dimension & Novice & Beginner & Learner & Intermediate & Expert \\
\hline Finance & $\begin{array}{c}\text { Store financial } \\
\text { data using } \\
\text { spreadsheets }\end{array}$ & $\begin{array}{c}\text { Store financial } \\
\text { data using hard } \\
\text { drives }\end{array}$ & $\begin{array}{c}\text { Store financial } \\
\text { data using } \\
\text { shared HDs }\end{array}$ & $\begin{array}{c}\text { Store financial } \\
\text { data using cloud }\end{array}$ & $\begin{array}{c}\text { Store financial } \\
\text { data using fog }\end{array}$ \\
\hline Ptrategy & $\begin{array}{c}\text { Store people's } \\
\text { data using } \\
\text { spreadsheets }\end{array}$ & $\begin{array}{c}\text { Store people's } \\
\text { data using hard } \\
\text { drives }\end{array}$ & $\begin{array}{c}\text { Store people's } \\
\text { data using } \\
\text { shared HDs }\end{array}$ & $\begin{array}{c}\text { Store people's } \\
\text { data using cloud }\end{array}$ & $\begin{array}{c}\text { Store people's } \\
\text { data using fog }\end{array}$ \\
\hline Process & $\begin{array}{c}\text { Store process } \\
\text { data using } \\
\text { spreadsheets }\end{array}$ & $\begin{array}{c}\text { Store process } \\
\text { data using hard } \\
\text { drives }\end{array}$ & $\begin{array}{c}\text { Store process } \\
\text { data using } \\
\text { shared HDs }\end{array}$ & $\begin{array}{c}\text { Store process } \\
\text { data using cloud }\end{array}$ & $\begin{array}{c}\text { Store process } \\
\text { data using fog }\end{array}$ \\
\hline Product & $\begin{array}{c}\text { Store product } \\
\text { data using } \\
\text { spreadsheets }\end{array}$ & $\begin{array}{c}\text { Store product } \\
\text { data using hard } \\
\text { drives }\end{array}$ & $\begin{array}{c}\text { Store product } \\
\text { data using } \\
\text { shared HDs }\end{array}$ & $\begin{array}{c}\text { Store product } \\
\text { data using cloud }\end{array}$ & $\begin{array}{c}\text { Store product } \\
\text { data using fog }\end{array}$ \\
\hline
\end{tabular}

Table 3 illustrates that not all organizational dimensions, in this case 'strategy', are affected by the cloud/storage toolbox. Additionally, some toolboxes may depend on other toolboxes/toolbox to perform their function. For example, the data stored in Table 3 have to be analyzed with the help of data analytics toolbox to truly create a "datadriven decision making" capability. The first level (novice) of data analytics toolbox is 
data collection, which is performed by the cloud/storage toolbox. The other maturity levels are data cleaning (beginner), data integration (learner), data reduction (intermediate) and data transformation (expert) respectively. These maturity levels are performed utilizing various statistical, optimization, machine learning, and artificial intelligence techniques. In case an SME uses only registers, logbooks and spreadsheets for their data collection, they can only support some short-term decision making processes, like planning for the number of products to be manufactured, the scheduling of workers shifts, etc. They will not be able to know the exact position of their product within the supply chain (i.e., traceability). On the other hand, if they can store data in the cloud (intermediate level), they might be able to get the shared and updated data from their customers, and therefore, they might be able to make better medium- and long-term decisions on the number of products to be produced and the scheduling of workers shifts. Similarly, they may now have the capability to know the location of their products across the supply chain. As an SME shifts towards the 'expert' maturity level, its overall awareness of its operational system increases. Thus, leading to a better, more mature, "data-driven decision making" capability.

\section{Results, Limitations and Future Work}

This paper introduced our new $S M^{3} E$ maturity model composed of five organizational dimensions, seven toolboxes and five maturity levels aimed at support manufacturing SMEs in their digital transformation towards SM/Industry 4.0.

An exemplary case based on the $S M^{3} E$ maturity model's cloud/storage toolbox was presented to showcase how data is stored and utilized based on the different organizational dimensions and maturity levels. This includes the use of different technologies from the toolboxes in order to create a "data-driven decision making" capability for the SME. Furthermore, it was illustrated how the different $S M^{3} E$ maturity model's toolboxes work together, in this case, to enhance the "data-driven decision making" capability in the discussion, i.e., the data analytics toolbox with the cloud/storage toolbox.

The limitation of this paper is that it presents only one (digital) capability: "datadriven decision making", which can be performed by deploying in this case the cloud/ storage toolbox in combination with the data analytical toolbox.

Future work will focus on the refinement and validation with SMEs of the proposed $S M^{3} E$ maturity model, and the later development of the adoption guidelines.

\section{References}

1. Husin, M.A., Ibrahim, M.D.: The Role of Accounting Services and Impact on SMEs Performance in Manufacturing Sector from East Coast Region of Malaysia: A Conceptual Paper. Procedia-Social and Behavioral Sciences, 115:54-67 (2014)

2. Tuyon, J., et al.: The Role of Microfinance in Development of Micro Enterprises in Malaysia. Business \& Management Quarterly Review, 2(3):47-57 (2011)

3. Jankowska, B., Götz, M., Główka, C.: Intra-Cluster Cooperation Enhancing SMEs' Competitiveness - The Role of Cluster Organisations in Poland. Investigaciones Regionales 39:195-214 (2017) 
4. Schiersch, A.: Inefficiency in the German Mechanical Engineering Sector. DIW Berlin, Discussion Paper No. 1949 (2009)

5. Maier, A., Student, D.: Industrie 4.0 - Der Große Selbstbetrug [In German] (2015) http://www.manager-magazin.de/magazin/artikel/digitale-revolution-industrie-4-0ueberfordert-deutschen-mittelstand-a-1015724.html

6. Balasingham, K.: Industry 4.0: Securing the Future for German Manufacturing Companies. Master's Thesis, University of Twente (2016)

7. Wendler, R.: The Maturity of Maturity Model Research: A Systematic Mapping Study. Information and Software Technology, 54(12):1317-1339 (2012)

8. Schumacher, A., Erol, S., Sihn, W.: A Maturity Model for Assessing Industry 4.0 Readiness and Maturity of Manufacturing Enterprises. Procedia CIRP, 52:161-166 (2016)

9. Jung, K., et al.: An Overview of a Smart Manufacturing System Readiness Assessment. In: Int'1. Conf. on Advances in Production Management Systems, pp. 705-712, Springer (2016)

10. Ganzarain, J., Errasti, N.: Three Stage Maturity Model in SME's toward Industry 4.0. J. of Industrial Engineering and Management, 9(5): 1119-1128 (2016)

11. Lichtblau, K., et al.: IMPULS-Industrie 4.0-Readiness. Impuls-Stiftung des VDMA, Aachen-Köln (2015) - http://www.impuls stiftung.de/documents/3581372/4875835/ Industrie+4.0+Readniness+IMPULS+Studie+Oktober+2015.pdf/447a6187-9759-4f25b186-b0f5eac69974

12. Geissbauer, R., Vedso, J., Schrauf, S.: Industry 4.0: Building the Digital Enterprise. Global Industry 4.0 Survey. PricewaterhouseCoopers (PwC), Munich (2016) - https://www. pwc.com/gx/en/industries/industries-4.0/landing-page/industry-4.0-building-your-digitalenterprise-april-2016.pdf

13. Schuh, G., Anderl, R., Gausemeier, J., Hompel, M., Wahlster, W.: Industrie 4.0 Maturity Index (2017) - http://www.acatech.de/fileadmin/user_upload/Baumstruktur_nach_Website/ Acatech/root/de/Publikationen/Projektbeichte/acatech_STUDIE_Maturity_Index_eng_WE B.pdf

14. Rockwell Automation: The Connected Enterprise Maturity Model (2014) - http:// literature. rockwellautomation.com/idc/groups/literature/documents/wp/cie-wp002_en-p.pdf

15. Gökalp, E., Şener, U., Eren, P.E.: Development of an Assessment Model for Industry 4.0: Industry 4.0-MM. In: Int'l. Conf. on Software Process Improvement and Capability Determination, pp. 128-142, Springer (2017)

16. Akdil, K.Y., Ustundag, A., Cevikcan, E.: Maturity and Readiness Model for Industry 4.0 Strategy. In Industry 4.0: Managing The Digital Transformation, pp. 61-94, Springer (2018)

17. Pöppelbuß, J., Röglinger, M.: What Makes a Useful Maturity Model? A Framework of General Design Principles for Maturity Models and its Demonstration in Business Process Management. In: 19th European Conf. on Information Systems, Paper No. 28 (2011)

18. Lasrado, L.A., Vatrapu, R., Andersen, K.N.: Maturity Models Development in is Research: A Literature Review. In: IRIS Selected Papers of the Information Systems Research Seminar in Scandinavia, Vol. 6 (2015)

19. Tao, F., Cheng, Y., Zhang, L., Nee, A.Y.: Advanced Manufacturing Systems: Socialization Characteristics and Trends. Journal of Intelligent Manufacturing, 28(5):1079-1094 (2017)

20. Lee, J., Jun, S., Chang, T.W., Park, J.: A Smartness Assessment Framework for Smart Factories Using Analytic Network Process. Sustainability, 9(5): 794-808 (2017)

21. Weyer, S., Schmitt, M., Ohmer, M., Gorecky, D.: Towards Industry 4.0: Standardization as the Crucial Challenge for Highly Modular, Multi-Vendor Production Systems. IFACPapersOnLine, 48(3):579-584 (2015)

22. Mittal, S., Romero, D., Wuest, T.: Towards a Smart Manufacturing Toolkit for SMEs. In: Proceedings of the 15th International Conference on Product Lifecycle Management (2018) 